\title{
IUMRS-ICAM2013 to be held in September 2013 in China
}

www.iumrs-icam2013.org/en

$\mathbf{T}$ he International Union of Materials Research Societies International Conference on Advanced Materials 2013 (IUMRS-ICAM2013) will

\section{3} be held on September 22-23, 2013 in Qingdao, China. The conference is hosted by the Materials Research Society of China, chaired by Society president Boyun Huang.

The program covers five topics: Energy and Environment Materials, Structural Materials, Functional Materials,
Nanoscale and Amorphous Materials, and Materials Processing and Genomic Engineering. In addition, the conference will offer an exhibit on advanced materials, manufacturing, and testing equipment.

IUMRS-ICAM provides the opportunity for scientists, engineers, and students from around the world to exchange their recent achievements in research and development in materials science and engineering. IUMRS-ICAM conferences are held every two years.
The abstract deadline is June 10, 2013.

More information is available from the conference website www.iumrsicam2013.org/en or by contacting the IUMRS-ICAM2013 Secretariat, Room 4102, No. 62, Zizhuyuan Road, Haidian District, Beijing, China, 100048; tel. 86-10-6872-2032 (Prof. Han) or 86-106871-0443 (Ms. Chen Hui); or email icam2013@163.com.

\section{IUMRS-ICA-2013 to be held in December 2013 in Bangalore} www.iumrs-ica2013.org.in

T he International Union of Materials Research Societies International Conference in Asia 2013 (IUMRSICA-2013) will be held on December 16-20, 2013 at the Indian Institute of Science (IISc) in Bangalore, India. This year's conference, chaired by S.B. Krupanidhi of IISc, is hosted by the Materials Research Society of India (MRS-I) and organized in conjunction with other academic and research institutions in the country.

The program features seven symposia: Electronic and Photonic Materials,
Functional Materials, Energy and Green Materials, Advanced Structural Materials, Materials for Bio/Medical Applications, Modeling, and Characterization. These will be complemented by Forums on Materials-Clean Water, Materials Education, and on Industry Academia Interaction.

Krupanidhi said, "Since the beginning of this series, this meeting has become a strong ground for a high-quality exchange of scientific results and ideas by researchers and scientists from both academia and industries. Furthermore, it also offers a strong platform to pre- sent and discuss cutting-edge research, to help both students and researchers for future collaborations."

The abstract deadline is July $\mathbf{3 1}$, 2013.

More information can be accessed from the conference website www. iumrs-ica2013.org.in or by contacting Prof. S.B. Krupanidhi, Vice PresidentGeneral Secretary, Materials Research Society of India, Indian Institute of Science, Bangalore 560 012, India; tel. 080-22932882/65334302; or email sbkica2013@gmail.com.

\section{E-MRS announces 2013 Spring and Fall Meetings} www.emrs-strasbourg.com

T he European Materials Research Society (E-MRS) celebrates its 30th anniversary this year. It will hold a special ceremony during the plenary session of this year's Spring Meeting, which will be held in Strasbourg, France, on May 28-30, 2013. The Society's Fall Meeting is scheduled for September 16-20, 2013 in Warsaw, Poland.

The Spring Meeting, chaired by Alain Claverie (CEMES/CNRS), Arnulf
Jaeger-Waldau (European Commission), Francesco Priolo (INFM-Universita di Catania), and Anke Weidenkaff (Empa), features symposia on Materials for Energy, Electronic and Photonic Materials, Advanced and Nano Materials, and Methods and Characterization. The Meeting will also present a workshop on "Protecting and securing our cultural heritage: diagnostics, characterization, conservation and restoration." The Meeting includes a tutorial and an equipment exhibit.
During the plenary session, on May 29th, Hideo Hosono (Tokyo Institute of Technology, Japan) will give a presentation on "Creating active functionality using lime and alumina: transparent metal, superconductivity and catalyst for ammonia synthesis," and Matthias Wuttig (RWTH Aachen University of Technology, Germany) will address "Phase change materials: from optical data storage to novel electronic memories." Award lectures will be pre- 
sented by Sir John Pendry (Imperial College London) for the Anniversary Prize, whose talk is titled "Metamaterials open new horizons in electromagnetism," and by Manuel Bibes (CNRS/ Thales, France), who has received the EU-40 Materials Prize. Bibes will address "Nanoferronics: controlling charge and spin currents by ferroic orders."
The E-MRS Fall Meeting will consist of 14 thematic symposia, a plenary session, and satellite events. It is chaired by George Kiriakidis of the Foundation for Research and TechnologyHellas (FORTH), Greece; Giuseppina Padeletti of ISMN-CNR, Italy; Witold Lojkowski of the Polish Academy of Sciences and Bialystok University of
Technology, Poland; and Wolfgang Jaeger of Christian-Albrechts-Universität, Germany.

The abstract deadline is June 10, 2013.

More information on both Meetings can be accessed at www.emrsstrasbourg.com.

\section{ICMAT2013 to be held in Singapore}

www.mrs.org.sg/icmat2013

T

he 7th International Conference on

Materials for Advanced Technologies (ICMAT2013) will be held on June 30 to July 5, 2013 in Singapore, hosted by the Materials Research Society of Singapore. The conference is chaired by B.V.R. Chowdari with Technical Chair Yuan Ping Feng, both from the National University of Singapore.

Symposia will cover Energy/Water Aspects, Nanoscience and Technology, Functional Materials, and Bio/Soft Materials.

Nobel laureate Alan Heeger (University of California-Santa Barbara) will present a plenary lecture on "The role of the Heisenberg unceertainty principle in bulk heterojunction solar cells" as well as a public lecture on "Creativity, discovery and risk: Nobel prizes past and future."

Nobel laureate Yuan-Tseh Lee (Academia Sinica, Taiwan) will also present a plenary and public lecture. The first lecture is titled "Elementary processes involved in matrix-assisted laser desorption ionization," and the public lecture will be on "Sustainable development of human society."

Other plenary speakers include Gabriel Aeppli (University College London, United Kingdom) addressing "The next life of silicon"; Andy Hor (National University of Singapore and Institute of Materials and Research Engineering
A*Star, Singapore), "Molecular design of catalytic materials through intelligent hybrid ligands"; and Helmuth Mohwald (Max-Planck-InstiMRS tute of Colloids and Interfaces, Germany), "Films and capsules from polyelectrolytes and nanoparticles for biomedical and materials applications."

More information can be accessed from the conference website www.mrs. org.sg/icmat2013 or by contacting Secretariat Office, Meeting Matters International, 1 Commonwealth Lane, \#06-23 One Commonwealth, Singapore 149544; tel. 65 6472 3108; or email icmat2013@ meetmatt.net.

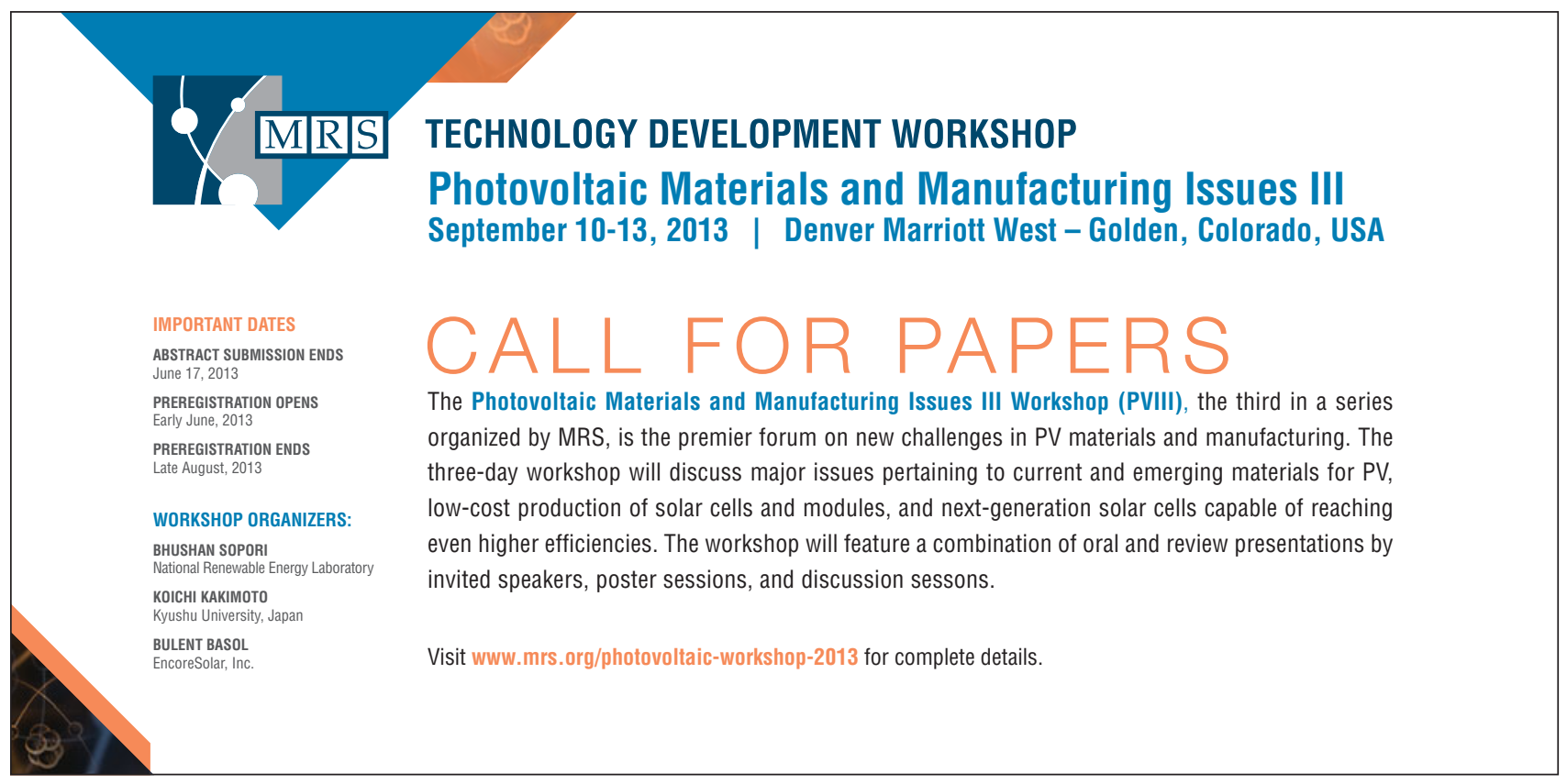

